\title{
A Parallel Adaptive Particle Swarm Optimization Algorithm for Economic/Environmental Power Dispatch
}

\author{
Jinchao Li, ${ }^{1}$ Jinying $\mathrm{Li}^{2}{ }^{2}$ Dongxiao Niu, ${ }^{1}$ and Yunna $\mathrm{Wu}^{1}$ \\ ${ }^{1}$ School of Economic and Management, North China Electric Power University, Beijing 102206, China \\ ${ }^{2}$ Department of Economic and Management, North China Electric Power University, \\ Baoding 071000, China \\ Correspondence should be addressed to Jinchao Li, gsyljch@163.com
}

Received 15 August 2012; Revised 15 November 2012; Accepted 20 November 2012

Academic Editor: Jung-Fa Tsai

Copyright (C) 2012 Jinchao Li et al. This is an open access article distributed under the Creative Commons Attribution License, which permits unrestricted use, distribution, and reproduction in any medium, provided the original work is properly cited.

\begin{abstract}
A parallel adaptive particle swarm optimization algorithm (PAPSO) is proposed for economic/environmental power dispatch, which can overcome the premature characteristic, the slow-speed convergence in the late evolutionary phase, and lacking good direction in particles' evolutionary process. A search population is randomly divided into several subpopulations. Then for each subpopulation, the optimal solution is searched synchronously using the proposed method, and thus parallel computing is realized. To avoid converging to a local optimum, a crossover operator is introduced to exchange the information among the subpopulations and the diversity of population is sustained simultaneously. Simulation results show that the proposed algorithm can effectively solve the economic/environmental operation problem of hydropower generating units. Performance comparisons show that the solution from the proposed method is better than those from the conventional particle swarm algorithm and other optimization algorithms.
\end{abstract}

\section{Introduction}

The electric power generation scheduling is one of the main optimization tasks in power systems. In planned economy pattern, the electric power generation dispatch is to realize power balance under the law of equal consumed energy ratio. With the electric power market reform, the breakup of monopolies creates competition, especially in the power generation side which realized the separation of electricity generation and transmission. In order to get much revenue, the power grid company attempts to schedule the committed generating units' outputs to meet the load demand at minimum production and transmission 
(operating) costs. This is the classical economic dispatch (ED) which is routinely used to minimize the market purchasing cost while fulfilling the operational constraints. In 1990s, due to the amendment of clean air act, economic/environmental dispatch (EED) formed at the base of emission dispatch (EMD), which simultaneously minimizes both fuel costs and pollutant emissions $[1,2]$. EED problem is a multiobjective mathematical programming problem which is concerned with the attempt to obtain the optimal solution. For these two contradictory objectives, fuel costs and pollutant emissions, individual optimization could not serve the purpose. Most techniques had been used to solve the economic/environmental dispatch (EED) problem. One of the solutions is to transfer two different objectives into a single objective by treating the emission as a constraint with a permissible limit [3]. Then some conventional methods such as the Bundle method [4], nonlinear programming $[5,6]$, mixed integer linear programming [7-10], dynamic programming [11], quadratic programming [12], the Lagrange relaxation method [13], network flow method [14], and direct search method [15] are used to solve such problems. It is unfortunately that the EED problem is a highly nonlinear optimization problem. Therefore, conventional optimization methods that make use of derivatives and gradients, in general, are not able to locate or identify the global optimum. There is still another research direction which converted the EED problem to a single objective by linear combination of different objectives as a weighted sum $[16,17]$ or price penalty factor approach [18]. Modern heuristic optimization techniques proposed by researchers based on operational research and artificial intelligence concepts are used to solve the problem. The studies on evolutionary algorithms have shown that these methods can be efficiently used to eliminate most of the difficulties of classical methods. The main intelligent algorithms include genetic algorithm [19], particle swarm optimization algorithm [20], and differential evolutionary algorithm [21]. Genetic algorithm is an optimizing searching method based on a biology evolutionary theory, which has disadvantages such as slow astringency and precocity [22]. Particle swarm optimization (PSO) is a newly emerging method for the swarm intelligence optimization, which has low precision and divergence problems [23]. Differential evolutionary algorithm (DE) can avoid the dependence effectively and has a good stability, but it is very time consuming and less efficient [24].

So it is still the kernel study topic that how to design a hybrid algorithm which works with high adaptability, high precision, and rapid computing efficiency.

In this paper, we developed PAPSO approach for solving the EED problem in the power system. The proposed multiobjective method for the EED was demonstrated to be feasible by the application in two different power systems.

This paper is organized as follows. In Section 2, the problem formulation is presented. In Section 3, the proposed approach is introduced. In Section 4, we present the studies of application cases and demonstrate the potential of the presented algorithm. Finally, in Section 5, the conclusions are given.

\section{Problem Formulation}

Economic/environmental generation dispatch is an optimization problem of determining the schedule of real power outputs of generating units within a power system with a number of constraints [25-27].

The economic/environmental power dispatch problem can be formulated as a multicriteria optimization model. 


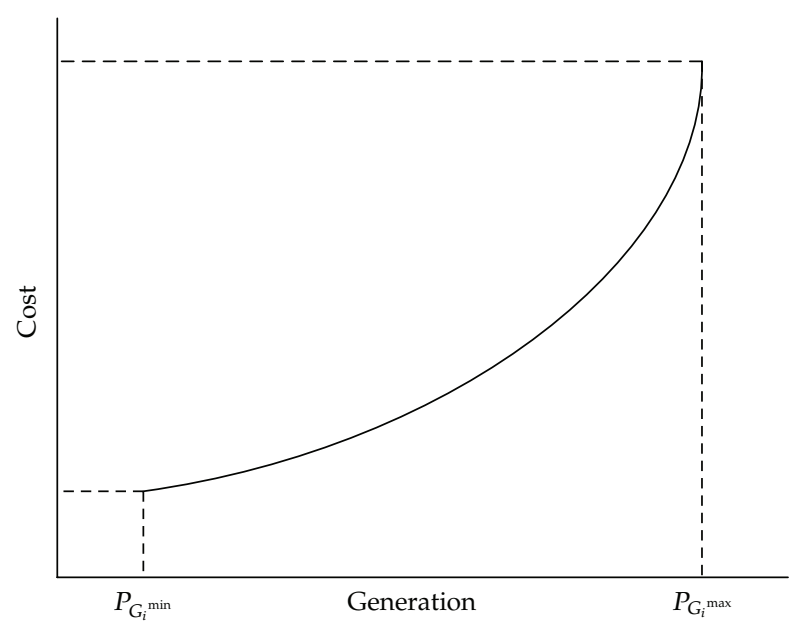

Figure 1: Cost function of generator.

\subsection{Problem Objectives}

\subsubsection{Minimization of Fuel Cost}

Let

$$
\min F_{t}=\sum_{i=1}^{N_{G}} F_{i}\left(P_{G i}\right)=\sum_{i=1}^{N_{G}}\left(a_{i} P_{G i}^{2}+b_{i} P_{G i}+c_{i}\right)
$$

where $F_{t}$ depresses the total generation cost which is represented by quadratic functions; $F_{i}$ is the cost function of $i$ th generator; $a_{i}, b_{i}$, and $c_{i}$ are the cost coefficients of $i$ th generator; $P_{G i}$ is the real power output of $i$ th generator; and $N_{G}$ is the number of generators. A typical cost function curve is shown in Figure 1.

\subsubsection{Minimization of Emission}

The total emission $E_{t}$ of atmospheric pollutants such as sulphur oxides $\mathrm{SO}_{x}$ and nitrogen oxides $\mathrm{NO}_{x}$ caused by fossil-fueled thermal units can be expressed as

$$
\min E_{t}=\sum_{i=1}^{N_{G}} E_{i}\left(P_{G i}\right)=\sum_{i=1}^{N_{G}}\left(\alpha_{i} P_{G i}^{2}+\beta_{i} P_{G i}+\gamma_{i}+\zeta_{i} \exp \left(\lambda_{i} P_{G i}\right)\right)
$$

where $\alpha_{i}, \beta_{i}, \gamma_{i}, \zeta_{i}$, and $\lambda_{i}$ are coefficients of the $i$ th generator emission characteristics. 


\subsection{Problem Constraints}

\subsubsection{Power Balance Constraint}

Let

$$
\sum_{i=1}^{N_{G}} P_{G i}=P_{D}+P_{L}
$$

where $P_{D}$ : total system demand in MW; $P_{L}$ : total system losses, which can be calculated by the Kron's loss formula; it is expressed in the quadratic form as follows:

$$
P_{L}=\sum_{i=1}^{N} \sum_{j=1}^{N} P_{G i} B_{i j} P_{G j}+\sum_{i=1}^{N} B_{0 i} P_{G i}+B_{00},
$$

where $B_{i j}, B_{0 i}$, and $B_{00}$ are the transmission network power loss $B$ coefficients, which are assumed to be constant, and reasonable accuracy can be achieved when the actual operating conditions are close to the base case where the $B$ coefficients were derived [28].

\subsubsection{Generation Capacity Constraint}

Let

$$
P_{G i}^{\min } \leq P_{G i} \leq P_{G i}^{\max }, \quad i=1, \ldots, N_{G}
$$

where $P_{\mathrm{G} i}^{\min }$ and $P_{\mathrm{G} i}^{\max }$ are the minimum and maximum generation limit $(\mathrm{MW})$ of $i$ th generator, respectively.

\subsubsection{Grid Capacity Constraint}

For secure operation, the actual transmission capacity must be restricted by its upper limit as

$$
S_{l i}\left(P_{G i}\right) \leq S_{l i}^{\max }, \quad i=1, \ldots, n l,
$$

where $n l$ is the number of transmission lines; $S_{l i}$ is the electric power flow of the $i$ th transmission line which is influenced by the $P_{G i}$; and $S_{l i}^{\max }$ is the upper limit of the $i$ th transmission line.

\subsection{Problem Formulation}

To solve a multiobjectives optimization problem, many traditional methods are transforming the multiobjectives into a single objective by averaging the objectives with a certain weight vector. 


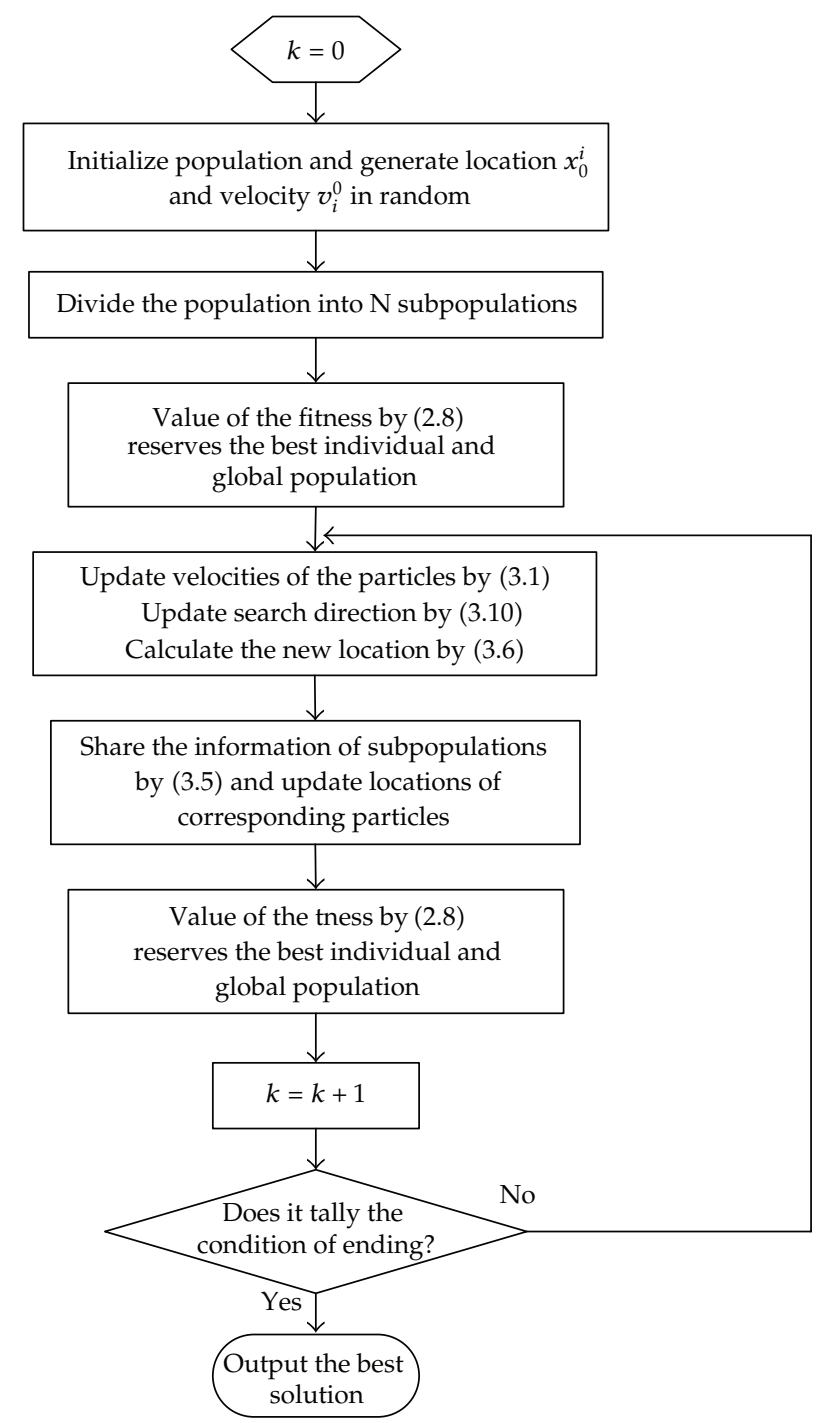

Figure 2: The flowchart of PAPSO.

In the economic/environmental dispatch problem, the two objectives are converted into a single objection by the price $V$ of emission which is calculated as follows:

$$
V=(\eta+1)\left(\frac{C_{1}}{Q_{1}}+\frac{C_{2}}{Q_{2}}\right),
$$

where $C_{1}$ is the antipollution equipment depreciation costs, $Q_{1}$ is maximum treatment capacity, $C_{2}$ is the operation cost of the antipollution equipment, $Q_{2}$ is the total amount of treatment pollution, and $\eta$ is the adjust coefficient. 


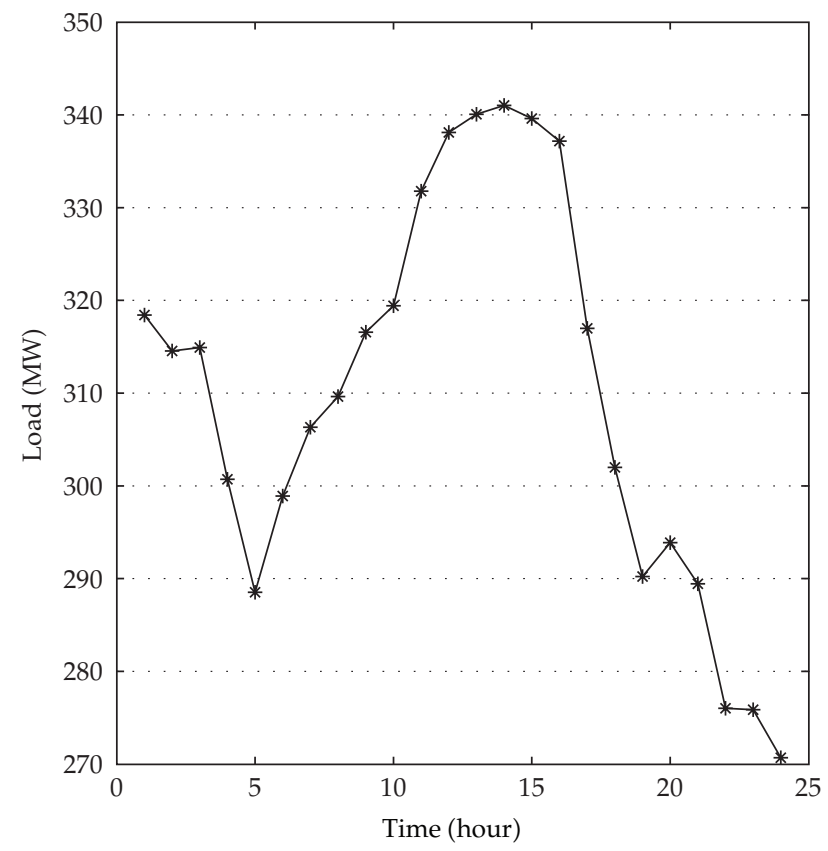

Figure 3: The total load curves with difference time intervals on one day.

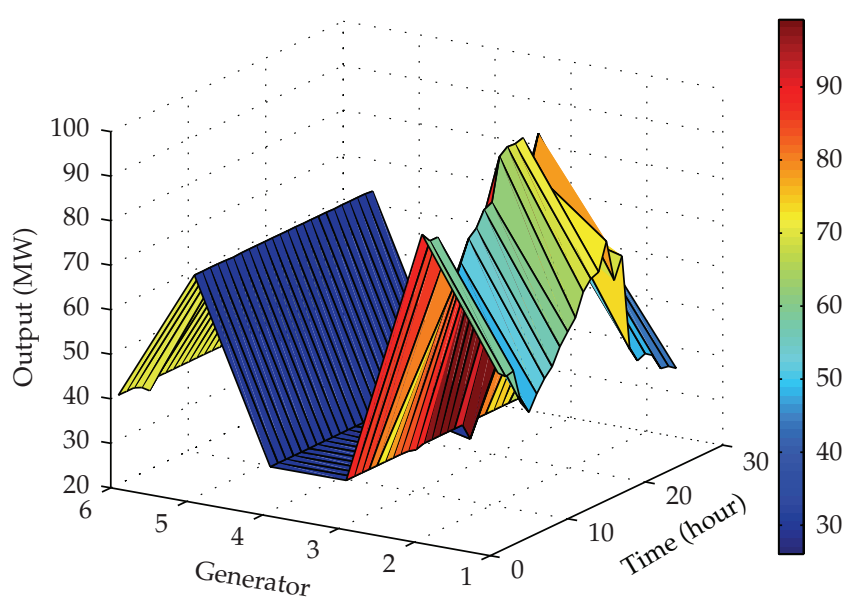

Figure 4: The results of EED by GA.

So the EED problem can be mathematically formulated as a single objective optimization problem as follows:

$$
\min F_{t}+V \times E_{t}
$$




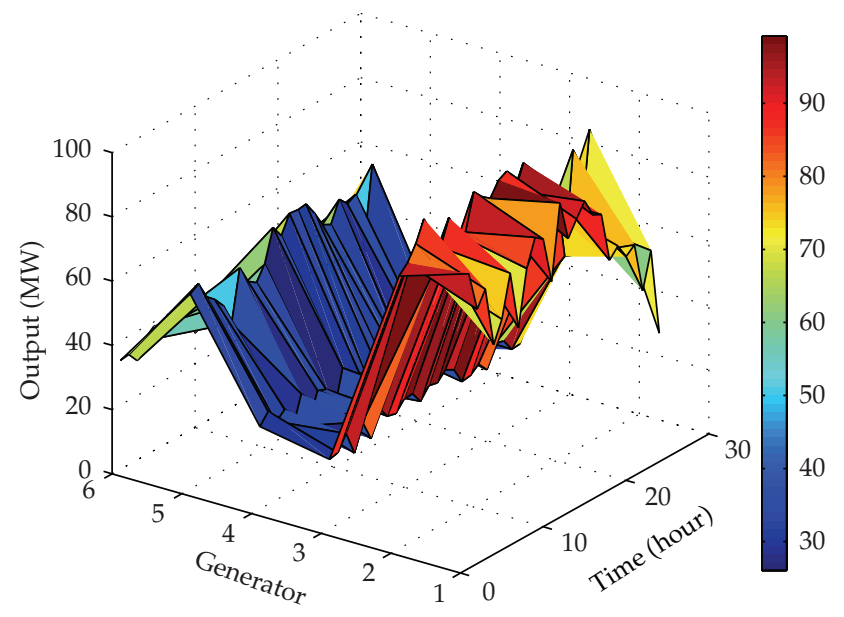

Figure 5: The results of EED by PSO.

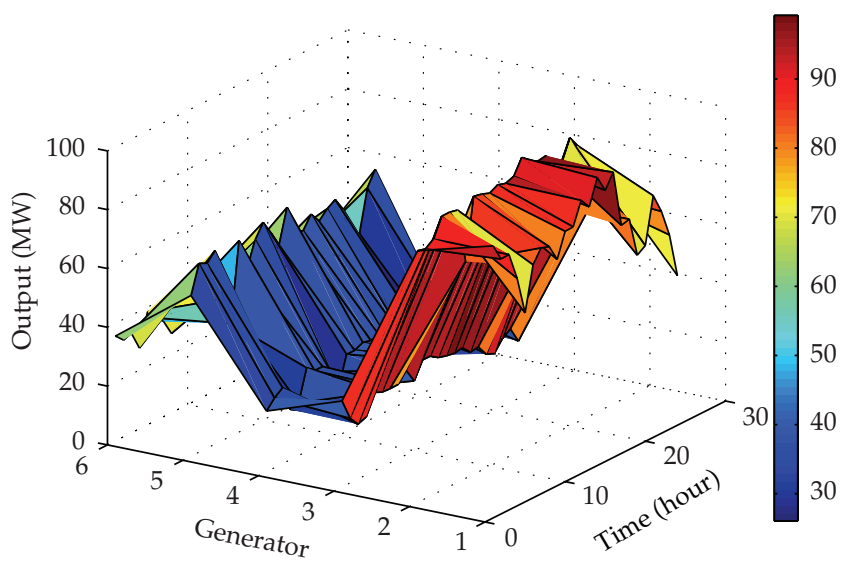

Figure 6: The results of EED by CFPSO.

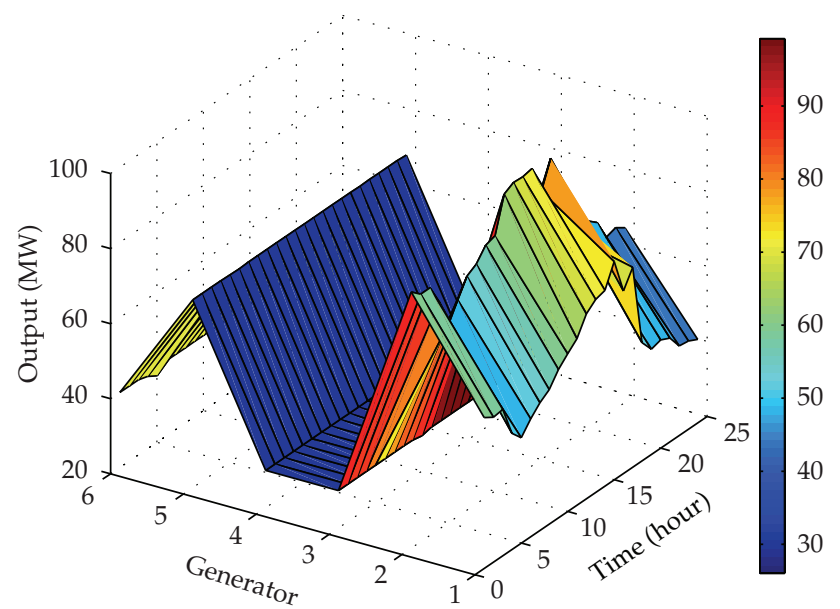

Figure 7: The results of EED by PAPSO. 


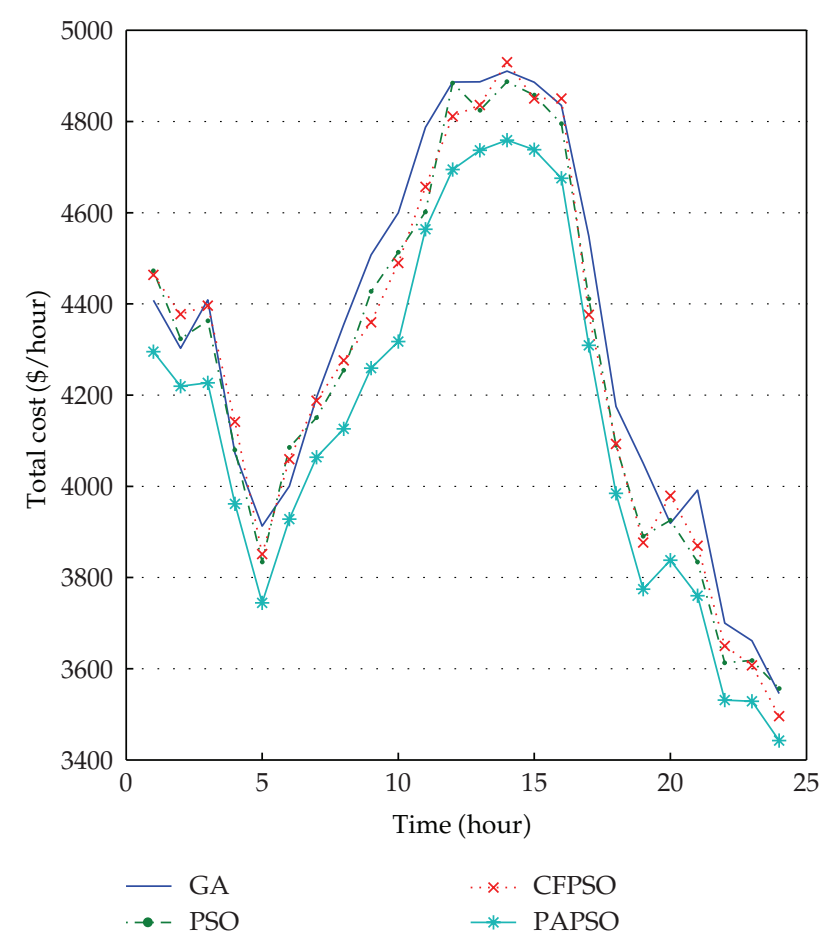

Figure 8: The total cost per hour by the different methods.

subject to

$$
\begin{aligned}
& g\left(P_{G}\right)=0 \\
& h\left(P_{G}\right) \leq 0,
\end{aligned}
$$

where $g$ is the equality constraint representing the power balance, while $h$ is the inequality constraint representing the generation capacity and power emission constraint.

\section{Overview of PSO}

\subsection{The Basic Principle of PSO}

Inspired by the movement pattern in a bird flock or fish school, Kennedy and Eberhart proposed the PSO algorithm in 1995 which is one of the modern heuristic optimization algorithms [29]. It is a population-based, self-adaptive, and heuristic optimization technique, which gets the optimization problem solution through the revision of individual action strategies based on information sharing and self-optimizing among the individuals. The classical PSO model consists of a swarm of particles moving in the $D$-dimensional space of possible problem solutions. In the $D$-dimensional space, each particle in the swarm is moved toward the optimal point in search of its optimal solution by adding a velocity with 
Table 1: The generator characteristic of the IEEE 30-bus system.

\begin{tabular}{lcccccc}
\hline $\begin{array}{l}\text { Generation } \\
\text { number }\end{array}$ & $\begin{array}{c}\text { Maximum } \\
(\mathrm{MW})\end{array}$ & $\begin{array}{c}\text { Minimum } \\
(\mathrm{MW})\end{array}$ & $\begin{array}{c}a \\
\left(\$ / \mathrm{MW}^{2} \mathrm{~h}\right)\end{array}$ & $\begin{array}{c}b \\
(\$ / \mathrm{MW})\end{array}$ & $\begin{array}{c}\alpha \\
\left(\mathrm{lb} / \mathrm{MW}^{2} \mathrm{~h}\right)\end{array}$ & $\begin{array}{c}\beta \\
(\mathrm{lb} / \mathrm{MWh})\end{array}$ \\
\hline 1 & 100 & 30 & 0.00375 & 2.000 & 0.023 & 1.2 \\
2 & 100 & 30 & 0.01750 & 1.700 & 0.015 & 1.5 \\
3 & 30 & 10 & 0.06250 & 1.000 & 0.013 & 2.1 \\
4 & 30 & 10 & 0.00834 & 3.250 & 0.014 & 2.4 \\
5 & 70 & 20 & 0.02500 & 3.000 & 0.012 & 2.3 \\
6 & 40 & 15 & 0.02500 & 3.000 & 0.013 & 2.5 \\
\hline
\end{tabular}

Table 2: Results of the IEEE 30 bus system under various methods.

\begin{tabular}{lccc}
\hline Method & Total cost $(\$)$ & CPU time $(\mathrm{ms})$ & Average convergence generations \\
\hline GA & 103546.64 & 166 & 1147 \\
PSO & 102294.4 & 185 & 1617 \\
CFPSO & 102488.1 & 132 & 542 \\
PAPSO & 99479.73 & 129 & 478 \\
\hline
\end{tabular}

its position. By doing so, the $i$ th particle gets the best position $P_{\text {besti, }}$, the best position of all particles is $G_{\text {best }}$. The position and velocity of the particle are modified by the following:

$$
\begin{gathered}
v_{i, j}^{k+1}=w v_{i, j}^{k}+c_{1} \operatorname{rand}_{1}\left(P_{\text {besti,j }}^{k}-x_{i, j}^{k}\right)+c_{2} \operatorname{rand}_{2}\left(G_{\text {best }, j}^{k}-x_{i, j}^{k}\right), \\
x_{i, j}^{k+1}=x_{i, j}^{k}+v_{i, j}^{k+1} \quad i=1, \ldots, N_{\text {par }}, j=1, \ldots, N_{D},
\end{gathered}
$$

where $k$ is the iteration count; $c_{1}$ and $c_{2}$ are the acceleration coefficients; rand $_{1}$ and rand $_{2}$ are uniformly distributed random numbers in the range of $[0,1] ; N_{D}$ is the dimension of the optimization problem (number of decision variables); $N_{\mathrm{par}}$ is the number of particles in the swarm; and $w$ is the inertia weight, it calculates by (3.3).

$$
w_{k}=w_{\max }-\frac{w_{\max }-w_{\min }}{k_{\max }} \times k
$$

where $w_{\max }$ and $w_{\min }$ are the initial value and stop value of $w ; k, k_{\max }$ are the number of iterations and the maximum number of iterations.

\subsection{Subgroups Information Sharing}

In order to solve the low precision and divergence problems of traditional PSO, the subgroups information sharing technique is introduced here. Based on the parallel algorithm, the initial swarms are divided into $N$ subgroups. Then the optimization process is done under the PAPSO. Because each subgroup searches optimization results separately, it is easy to fall 
Table 3: The generator characteristic of the IEEE 30-bus system.

\begin{tabular}{lcccccc}
\hline $\begin{array}{l}\text { Generation } \\
\text { number }\end{array}$ & $\begin{array}{c}\text { Maximum } \\
(\mathrm{MW})\end{array}$ & $\begin{array}{c}\text { Minimum } \\
(\mathrm{MW})\end{array}$ & $\begin{array}{c}a \\
\left(\$ / \mathrm{MW}^{2} \mathrm{~h}\right)\end{array}$ & $\begin{array}{c}b \\
(\$ / \mathrm{MWh})\end{array}$ & $\begin{array}{c}\alpha \\
\left(\mathrm{lb} / \mathrm{MW}^{2} \mathrm{~h}\right)\end{array}$ & $\begin{array}{c}\beta \\
(\mathrm{lb} / \mathrm{MWh})\end{array}$ \\
\hline 1 & 250 & 100 & 0.0561 & 7.92 & 1.355 & 0.0126 \\
2 & 100 & 25 & 0.0310 & 7.85 & 1.249 & 0.01375 \\
3 & 50 & 10 & 0.078 & 7.97 & 0.805 & 0.00765 \\
4 & 25 & 10 & 0.075 & 7.77 & 0.902 & 0.00693 \\
5 & 10 & 5 & 0.077 & 7.54 & 0.795 & 0.0045 \\
6 & 250 & 100 & 0.0561 & 7.92 & 1.355 & 0.0126 \\
7 & 100 & 20 & 0.0310 & 7.85 & 1.249 & 0.01375 \\
8 & 50 & 10 & 0.067 & 7.21 & 0.992 & 0.0032 \\
9 & 75 & 25 & 0.078 & 7.97 & 0.805 & 0.00765 \\
10 & 50 & 10 & 0.065 & 7.23 & 0.902 & 0.00693 \\
11 & 75 & 15 & 0.077 & 7.54 & 0.795 & 0.0045 \\
12 & 550 & 100 & 0.0561 & 7.92 & 1.355 & 0.0126 \\
13 & 100 & 25 & 0.0210 & 4.85 & 1.249 & 0.01375 \\
14 & 500 & 100 & 0.0530 & 7.77 & 0.905 & 0.00765 \\
15 & 400 & 50 & 0.0411 & 6.57 & 1.302 & 0.00693 \\
\hline
\end{tabular}

Table 4: Results of the IEEE 57-bus system under various methods for a demand of 1950 MW.

\begin{tabular}{lccc}
\hline Method & Total cost $(\$)$ & CPU time $(\mathrm{ms})$ & Convergence generations \\
\hline GA & 130831.82 & 718 & 2661 \\
PSO & 133442.56 & 359 & 1585 \\
CFPSO & 114515.42 & 829 & 4635 \\
PAPSO & 105605.30 & 353 & 1306 \\
\hline
\end{tabular}

into the local extreme value point and to be "premature." In order to solve this problem, the crossover operator is introduced, which is shown in the following:

$$
x_{n_{s} d, \text { worst }}= \begin{cases}x_{l d, \text { best }}, & \text { if } r \leq 0.5 \\ x_{n_{s} d, \text { worst }}, & \text { else, }\end{cases}
$$

where $r$ is the random numbers in the range of $[0,1] ; x_{n_{s}} d$,worst is the $d$ th component of the $s$ th vector among the $n$th group; $x_{l d, \text { best }}$ is the $d$ th component of the best position vector in the $l$ th group; $s, n, l=1,2, \ldots, N-1$ and $n \neq l$.

\subsection{Adaptive Updates of the Search Direction}

It is obviously shown in (3.2) that particles' locations update are only simple sum of particles' former location and update speeds. While the particles' speed update is influenced by the parameters $w, c_{1}, c_{2}, \operatorname{rand}_{1}$, and $\operatorname{rand}_{2}$. It is possible that the speed update may be at the wrong direction. It will slow down the convergence speed and make the performance of the 
algorithm bad. So the search direction variable $d_{i d}^{k}$ is introduced to realize the adaptive update of the particle location; the updated formula is shown in the following:

$$
x_{i, d}^{k+1}=x_{i, d}^{k}+d_{i d}^{k} \cdot\left|v_{i, d}^{k+1}\right|,
$$

where $d_{i d}^{k}$ express the $d$ th component of the search direction variable at the $k+1$ iteration.

The behavior of the information exchange among the particles during the optimization at solution space can be called coordination. So the search direction of every particle has closed relationship with the coordination behavior among the particles. The behaviors can be divided into two kinds: one is egotistic direction, and the other is altruistic behavior. Under egotistic direction, the particle's search direction is expressed as follows:

$$
d_{i, \text { ego }}^{k}=\operatorname{sign}\left(P_{\text {besti }}^{k}-x_{i}^{k}\right),
$$

where $\operatorname{sign}(\cdot)$ is sign function which gets the corresponding element determined by the variable $P_{\text {besti }}^{k}-x_{i}^{k}$, if $P_{\text {besti }}^{k}-x_{i}^{k}>0, \operatorname{sign}\left(P_{\text {besti }}^{k}-x_{i}^{k}\right)=+1$, if $P_{\text {besti }}^{k}-x_{i}^{k}=0, \operatorname{sign}\left(P_{\text {besti }}^{k}-x_{i}^{k}\right)=0$, if $P_{\text {besti }}^{k}-x_{i}^{k}<0, \operatorname{sign}\left(P_{\text {besti }}^{k}-x_{i}^{k}\right)=-1$.

Under altruistic behavior, the particles in the same subgroup collaborate clearly, and they exchange information each other and adjust their behavior according to the other particle movement to achieve the target. The altruistic behavior can be expressed as follows:

$$
\begin{aligned}
& d_{i, \text { alt } 1}^{k}=\operatorname{sign}\left(G_{\text {best } j}^{k}-x_{i}^{k}\right), \\
& d_{i, \text { alt2 }}^{k}=\operatorname{sign}\left(l_{\text {best } j}^{k}-x_{i}^{k}\right),
\end{aligned}
$$

where $G_{\text {best } j}^{k}$ is history best position of other particles expect $i$ th particle. $1_{\text {best } j}^{k}$ is current best position of other particles expect $i$ th particle.

Besides the egotistic and altruistic behavior, particle also has proactiveness behavior which does not act simply following the environment change. The proactiveness direction can be expressed as follows:

$$
d_{i, \text { pro }}^{k}=\operatorname{sign}\left(x_{i}^{k_{1}}-x_{i}^{k_{2}}\right)
$$

where $k_{1}, k_{2} \in\{k, k-1, k-2\}, x_{i}^{k_{1}}$ is better than $x_{i}^{k_{2}}$. Actually, the search direction of the $i$ th particle is determined by the compromise of $d_{i, \text { ego }}^{k} d_{i, \text { alt1 }}^{k}, d_{i, \text { alt2 }}^{k}$ and $d_{i, \text { pro }}^{k}$. Here we used the method of selection in formula (3.7) to get the $d$ th component $d_{i d}^{k}$ in the $i$ th particle's search direction vector. The formula is shown in the following:

$$
d_{i d}^{k}= \begin{cases}0, & \text { if } r_{d} \leq p_{d}^{(0)} \\ +1, & \text { if } p_{d}^{(0)}<r_{d} \leq p_{d}^{(0)}+p_{d}^{(+1)} \\ -1, & \text { if } p_{d}^{(0)}+p_{d}^{(+1)}<r_{d} \leq 1\end{cases}
$$


where $r_{d}$ is the evenly distributed random number on the internal $[0,1] \cdot p_{d}^{(m)}(m \in 0,+1,-1)$ express the percentage of $m$ in the assemble $\left\{d_{i d, \text { ego }}^{k}, d_{i d, \text { alt } 1,}^{k}, d_{i d, \text { alt } 2}^{k}, d_{i d, \text { pro }}^{k}\right\}$.

\subsection{The Procedure of PAPSO}

The procedures of the PAPSO are shown in Figure 2.

The steps of the PAPSO are listed below.

Step 1. Setting the initial parameters, including the particle size $N_{\text {par }}$, the total iterations number $T$, and the initial position $x_{i}^{0}$.

Step 2. Dividing the parent population into $N$ subgroups.

Step 3. Using (2.8) to calculate the fitness of the EED problem.

Step 4. Taking the current position of each particle as best position, recording the subgroup's best position and global best position.

Step 5. Using (3.1), (3.5), and (3.10) to calculate the next positions of the particles.

Step 6. Using (3.4) realizing the information sharing among the subgroups.

Step 7. Calculating the fitness of the EED problem by (2.8), if fitness value is better than the former, recording the new positions of the particles.

Step 8. Judge whether meet the algorithm termination conditions. If meeting, ending the algorithm, otherwise turning to Step 5.

\section{Simulation and Results}

The proposed PAPSO method for EED problem is validated and tested on the IEEE 30bus with 6-unit system [30] and 57-bus with 15-unit system [31]. In order to illustrate the performance of PAPSO, the EED schedule with emission and cost of generating units were obtained with system and power flow constraints using a different intelligent such as GA, PSO, CFPSO (Constriction Factor Particle Swarm Optimization), and PAPSO. Table 1 gives the generator characteristic of the IEEE 30-bus with 6-unit system.

The demand load of 24 hours is shown in Figure 3, the price of emission $V=\$ 3.56 / \mathrm{lb}$. The simulation results are shown in Figures 4, 5, 6, and 7. The results show that the PAPSO has the best smooth dispatch schedule than the others. The total variance of schedule by PAPSO is 224.71, while the total variances of schedule by GA, PSO, and CFPSO are 494.66, 358.54, and 319.48 , respectively. The total costs per hour by the different methods are shown in Figure 8. Figure 8 shows that the PAPSO has the best dispatch schedule than the others. Table 2 shows that the proposed PAPSO provides the lower total cost as well as the less CPU execution time for all the GA, PSO, and CFPSO methods. Table 3 shows the generator characteristic of the IEEE 57-bus with the 15-unit system. The results tested by the 57-bus with the 15-unit system are shown in Table 4. 


\section{Conclusions}

In this paper, we propose a combined intelligent algorithm (PAPSO) and compare with traditional GA, PSO, and CFPSO algorithm to solve economic/environmental power dispatch problems with unit, line flow constraints. By analyzing the power operation cost, energy consumption, and emission cost in detail, the single-objective optimization model of economic/environmental dispatch is established. Then IEEE 30-bus with 6-unit system and IEEE57-bus with 15-unit system are used to testify the proposed method. The results display a satisfactory performance by PAPSO, with respect to both the quality of its evolved solutions and the computational requirements. This algorithm gives a realistic solution for dealing with future economic/environmental generation dispatch problems.

\section{Acknowledgments}

The authors thank the editor and the reviewers whose comments improved the quality of this study. This work was supported by "NSFC under Grant no. 71071052," "the Fundamental Research Funds for the Central Universities no. 12MS74," and "China Postdoctoral Science Foundation no. 2012M520221".

\section{References}

[1] R. Petrovic and B. Kralj, "Economic and environmental power dispatch," European Journal of Operational Research, vol. 64, no. 1, pp. 2-11, 1993.

[2] J. H. Talaq, F. El-Hawary, and M. E. El-Hawary, "Summary of environmental/economic dispatch algorithms," IEEE Transactions on Power Systems, vol. 9, no. 3, pp. 1508-1516, 1994.

[3] G. P. Granelli, M. Montagna, G. L. Pasini, and P. Marannino, "Emission constrained dynamic dispatch," Electric Power Systems Research, vol. 24, no. 1, pp. 55-64, 1992.

[4] A. J. Mezger and K. C. de Almeida, "Short term hydrothermal scheduling with bilateral transactions via bundle method," International Journal of Electrical Power and Energy Systems, vol. 29, no. 5, pp. 387-396, 2007.

[5] S. J. P. S. Mariano, J. P. S. Catalão, V. M. F. Mendes, and L. A. F. M. Ferreira, "Profit-based short-term hydro scheduling considering head-dependent power generation," in Proceedings of the IEEE Power Tech Conference, pp. 1362-1367, July 2007.

[6] L. J. Martinez, T. A. Lora, and R. J. Santos, "Short term hydrothermal coordination based on interior point nonlinear programming and genetic Algorithm," in Proceedings of the IEEE Porto Power Tech Conference, 2001.

[7] C. W. Gar, M. Aganagic, J. G. Waight et al., "Experiences with mixed integer linear programming based approaches on short-term hydro scheduling," IEEE Transactions on Power Systems, vol. 16, no. 4, pp. 743-749, 2001.

[8] G. W. Chang, M. Aganagic, J. G. Waight et al., “Experiences with mixed integer linear programming based approaches on short-term hydro scheduling," IEEE Transactions on Power Systems, vol. 16, no. 4, pp. 743-749, 2001.

[9] J. Garcia-Gonzalez and G. Alonso Castro, "Short term hydro scheduling with cascaded and head dependent reservoir based on mixed integer linear programming," in Proceedings of the IEEE Porto Power Tech Conference, vol. 3, pp. 758-765, 2001.

[10] J. García-González and G. Alonso Castro, "Profit based optimal scheduling of a hydro chain in the day ahead electricity market," European Journal of Operational Research, vol. 18, no. 1, pp. 1354-1369, 2007.

[11] C. C. Shi, H. C. Chun, I. K. Fomg, and P. B. Lah, "Hydroelectric generation scheduling with an effective differential dynamic programming algorithm," IEEE Transactions on Power System, vol. 5, no. 3, pp. 737-743, 1990. 
[12] C. Erion Finardi, L. D. Silva Edson, and C. V. Laudia Sagastizabal, "Solving the unit commitment problem of hydropower plants via Lagrangian relaxation and sequential quadratic programming," Computational \& Applied Mathematics, vol. 24, no. 3, pp. 23-35, 2005.

[13] S. Tkayuki and W. Kamu, "Lagrangian relaxation method for price based unit commitment problem," Engineering Optimization Taylor Francis, vol. 36, no. 6, pp. 705-719, 2004.

[14] P. E. C. Franco, M. F. Carvalho, and S. Soares, "Network flow model for short-term hydro-dominated hydrothermal scheduling problems," IEEE Transactions on Power Systems, vol. 9, no. 2, pp. 1016-1022, 1994.

[15] A. J. Wood and B. F. Wollenberg, Power Generation Operation and Control, John Wiley \& Sons, New York, NY, USA, 1984.

[16] J. S. Dhillon, S. C. Parti, and D. P. Kothari, "Stochastic economic emission load dispatch," Electric Power Systems Research, vol. 26, no. 3, pp. 179-186, 1993.

[17] C. S. Chang, K. P. Wong, and B. Fan, "Security-constrained multi-objective generation dispatch using bicriterion global optimization," IEE Proceedings of Generation, Transmission and Distribution, vol. 142, no. 4, pp. 406-414, 1995.

[18] A. I. S. Kumar, K. Dhanushkodi, J. J. Kumar, and C. K. C. Paul, “Particle swarm optimization solution to emission and economic dispatch problem," in Proceedings of the IEEE Region 10th International Conference, pp. 748-759, 2001.

[19] H. H. Chang, "Genetic algorithms and non-intrusive energy management system based economic dispatch for cogeneration units," Energy, vol. 36, no. 1, pp. 181-190, 2011.

[20] D. N. Jeyakumar, T. Jayabarathi, and T. Raghunathan, "Particle swarm optimization for various types of economic dispatch problems," International Journal of Electrical Power and Energy Systems, vol. 28, no. 1, pp. 36-42, 2006.

[21] S. Sivasubramani and K. S. Swarup, "Environmental/economic power dispatch problem using multiobjective differential evolution algorithm," Electric Power Systems Research, vol. 88, pp. 1171-1181, 2010.

[22] M. Kop and X. Liu, "Texture detection by genetic programming," in Proceedings of the Congress on Evolutionary Computation, pp. 867-872, May 2001.

[23] T. Qiaoling, Z. Xuecheng, Z. Qiao, G. Fei, and H. Tong, "The hardware/software partitioning in embedded system by improved particle swarm optimization algorithm," in Proceedings of the 5th IEEE International Symposium on Embedded Computing (SEC '08), pp. 43-46, October 2008.

[24] S. W. Leung, S. Y. Yuen, and C. K. Chow, "Parameter control system of evolutionary algorithm that is aided by the entire search history," Applied Soft Computing, vol. 12, no. 9, pp. 3063-3078, 2012.

[25] M. A. Abido, "A novel multiobjective evolutionary algorithm for environmental/economic power dispatch," Electric Power Systems Research, vol. 65, no. 1, pp. 71-81, 2003.

[26] D. W. Gong, Y. Zhang, and C. L. Qi, "Environmental/economic power dispatch using a hybrid multiobjective optimization algorithm," International Journal of Electrical Power and Energy Systems, vol. 32, no. 6, pp. 607-614, 2010.

[27] L. Wang and C. Singh, "Reserve-constrained multiarea environmental/economic dispatch based on particle swarm optimization with local search," Engineering Applications of Artificial Intelligence, vol. 22, no. 2, pp. 298-307, 2009.

[28] H. Saadat, Power System Analysis, The McGraw-Hill Companies, New York, NY, USA, 1999.

[29] J. Kennedy and R. Eberhart, "Particle swarm optimization," in Proceedings of the IEEE International Conference on Neural Networks, pp. 1942-1948, December 1995.

[30] A. Farag, S. Al-Baiyat, and T. C. Cheng, "Economic load dispatch multiobjective optimization procedures using linear programming techniques," IEEE Transactions on Power Systems, vol. 10, no. 2, pp. 731-738, 1995.

[31] S. Balakrishnana, P. S. Kannanb, C. Aravindanc, and P. Subathra, "On-line emission and economic load dispatch using adaptive Hopfield neural network," Applied Soft Computing, vol. 2, pp. 297-305, 2003. 


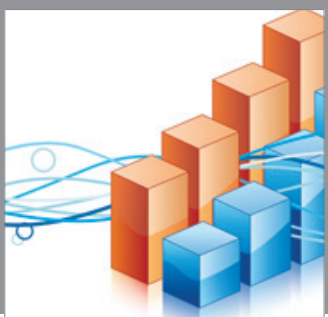

Advances in

Operations Research

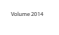

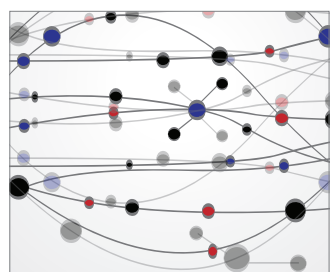

\section{The Scientific} World Journal
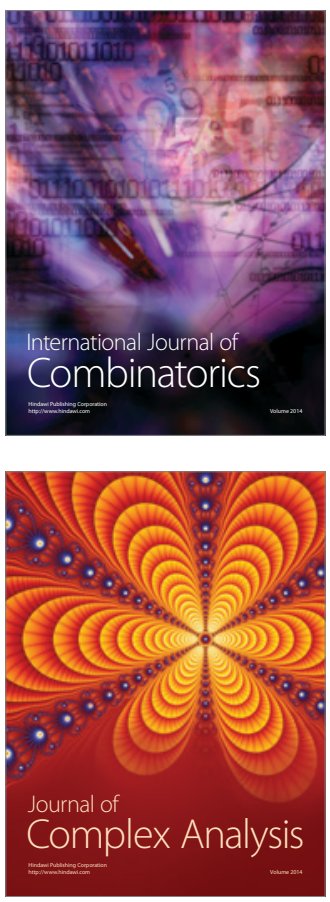

International Journal of

Mathematics and

Mathematical

Sciences
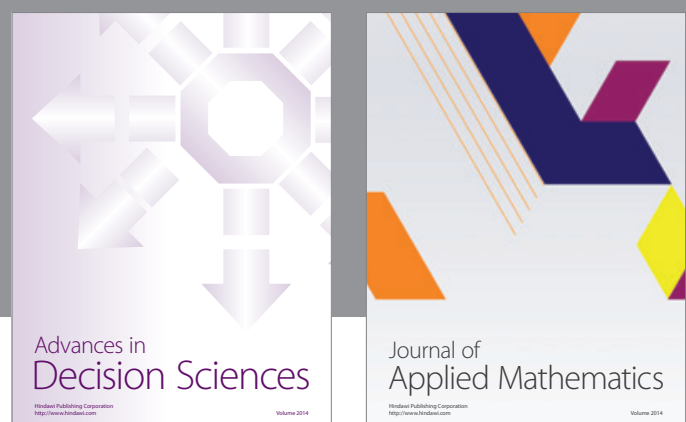

Journal of

Applied Mathematics
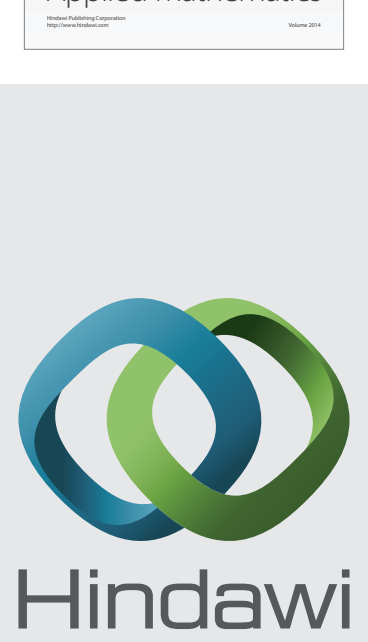

Submit your manuscripts at http://www.hindawi.com
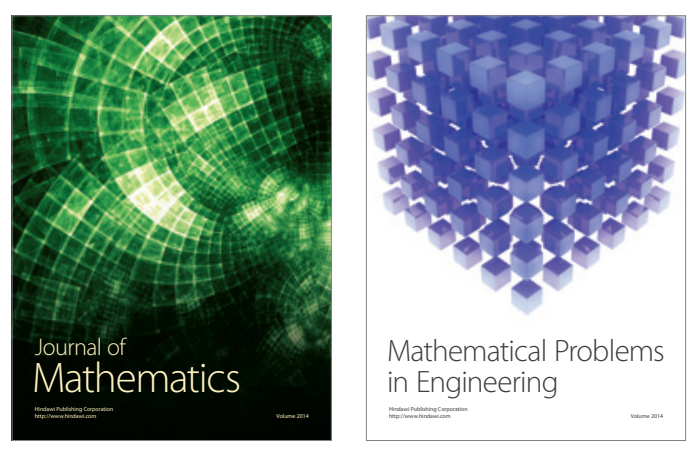

Mathematical Problems in Engineering
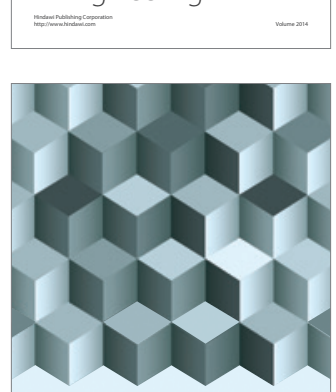

Journal of

Function Spaces
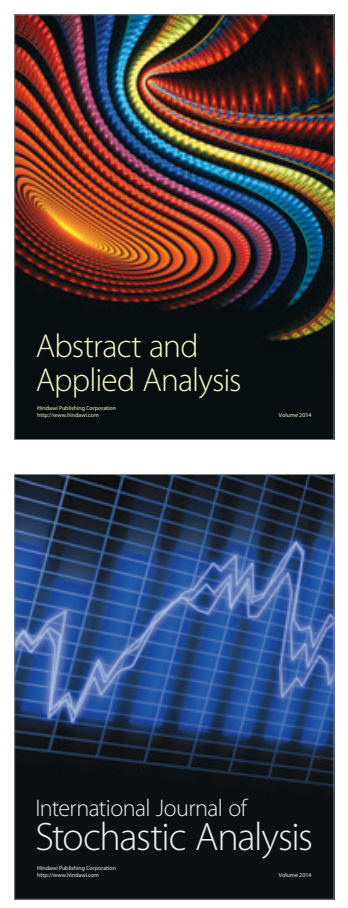

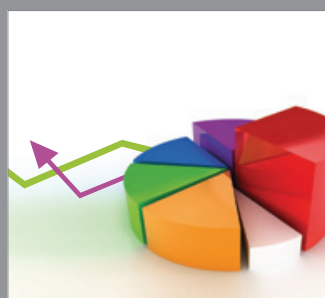

ournal of

Probability and Statistics

Promensencen
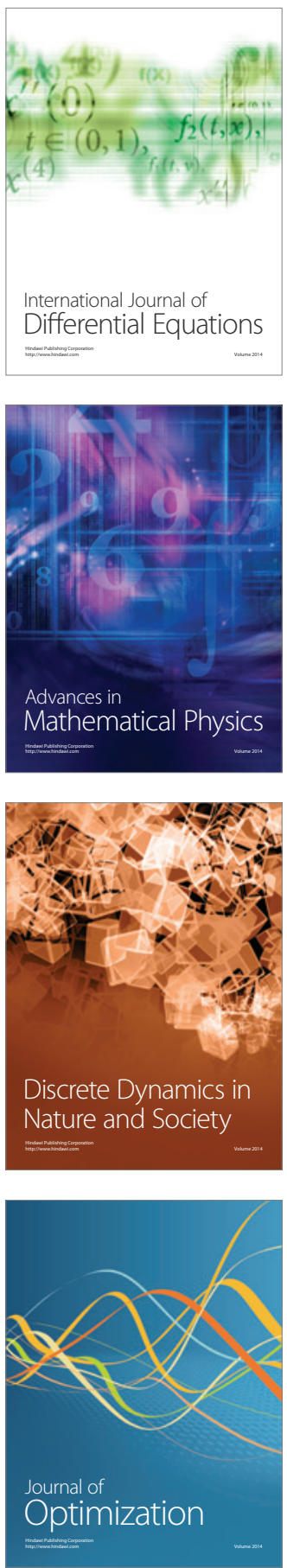